\title{
Imaging of retinal ganglion cells in glaucoma: pitfalls and challenges
}

\author{
R. M. Werkmeister • A. Popa Cherecheanu • \\ G. Garhofer • D. Schmidl • L. Schmetterer
}

Received: 30 January 2013 / Accepted: 21 February 2013 /Published online: 20 March 2013

(C) The Author(s) 2013. This article is published with open access at Springerlink.com

\begin{abstract}
Imaging has gained a key role in modern glaucoma management. Traditionally, interest was directed toward the appearance of the optic nerve head and the retinal nerve fiber layer. With the improvement of the resolution of optical coherence tomography, the ganglion cell complex has also become routinely accessible in the clinic. Further advances have been made in understanding the structurefunction relationship in glaucoma. Nevertheless, direct imaging of the retinal ganglion cells in glaucoma would be advantageous. With the currently used techniques, this goal cannot be achieved, because the transversal resolution is limited by aberrations of the eye. The use of adaptive optics has significantly improved transversal resolution, and the imaging of several cell types including cones and astrocytes has become possible. Imaging of retinal ganglion cells, however, still remains a problem, because of the transparency of these cells. However, the visualization of retinal ganglion cells and their dendrites has been achieved in animal models. Furthermore, attempts have been made to
\end{abstract}

The work of the authors was supported by the Austrian Science Foundation (FWF) project no. APP21570FW, the Austrian Research Promotion Agency (FFG) project no. FA607A0502 and the Christian Doppler Laboratory for Laser Development and their Application in Medicine.

R. M. Werkmeister $\cdot$ D. Schmidl $\cdot$ L. Schmetterer $(\bowtie)$ Center for Medical Physics and Biomedical Engineering, Medical University of Vienna, Währinger Gürtel 18-20, 1090, Vienna, Austria

e-mail: leopold.schmetterer@meduniwien.ac.at

A. P. Cherecheanu

Department of Ophthalmology, Emergency University Hospital, Splaiul Independentei 169, District 5,

Bucharest, Romania

G. Garhofer $\cdot$ D. Schmidl $\cdot$ L. Schmetterer

Department of Clinical Pharmacology,

Medical University of Vienna, Währinger Gürtel 18-20,

1090, Vienna, Austria visualize the apoptosis of retinal ganglion cells in vivo. Implementation of these techniques in clinical practice will probably improve glaucoma care and facilitate the development of neuroprotective strategies.

Keywords Glaucoma $\cdot$ Retinal ganglion cells $\cdot$ Adaptive optics · Optical coherence tomography $\cdot$ Imaging

\section{Introduction}

Glaucoma is a progressive optic neuropathy associated with characteristic functional (visual field loss) and structural (optic disc damage) defects. The disease is associated with the loss of retinal ganglion cells (RGCs) in the inner retina and of their axons in the optic nerve head (ONH). Nerve fibers of RGCs pass out of the eye at the $\mathrm{ONH}$ and their loss is associated with characteristic changes in $\mathrm{ONH}$ morphology.

The most important known risk factor for glaucoma is increased intraocular pressure (IOP). The reduction of IOP is associated with reduced progression of the disease (Quigley 2011) as evidenced by several large-scale clinical trials. The measurement of IOP, however, has little value in the diagnosis and monitoring of the progression of the disease, because a significant portion of patients with primary open angle glaucoma have IOP levels in the normal range and because many subjects do not develop glaucoma, despite elevated IOP values (Quigley 2011).

Whereas the reduction of IOP offers, for glaucomatous optic neuropathy, a treatment option that is not available for other neurodegenerative diseases, the pathophysiology of glaucoma remains largely speculative. Theories have been formulated focusing on various aspects of the disease including oxidative stress and mitochondrial dysfunction (Agudo-Barriuso et al. 2013; Osborne 2010), the immune system (Gramlich et al. 2013; Tezel 2013), ocular 
biomechanics (Burgoyne 2011; Strouthidis and Girard 2013), vascular factors (Cherecheanu et al. 2013; Mozaffarieh and Flammer 2013; Resch et al. 2009; Schmidl et al. 2011) and brain involvement (Engelhorn et al. 2012; Nucci et al. 2013; Yucel and Gupta 2008). A unified theory covering all facets of glaucoma has, however, not yet been presented.

Imaging of the retina and $\mathrm{ONH}$ has become increasingly important in glaucoma management during the last few years. As compared with neurodegenerative diseases in the brain, the posterior pole of the eye is more easily accessible for diagnostic imaging through the clear ocular media. Recently, our understanding of the structure-function relationship in glaucoma has also significantly increased (Malik et al. 2012; Medeiros et al. 2012). Imaging in glaucoma patients focuses on the $\mathrm{ONH}$, the retinal nerve fiber layer and the RGC layer. Among these options, the imaging of RGCs is the most promising approach, because the loss of RGCs is directly associated with the characteristic glaucomatous loss of visual field. The present review focuses on the current imaging modalities in glaucoma and on approaches to visualize RGCs in vivo.

\section{Current status of imaging in glaucoma}

For a long time, the imaging of the $\mathrm{ONH}$ and the retina was mainly performed by fundus photography or ophthalmoscopy. Images can be taken stereoscopically and either viewed through a stereo viewer or on a computer monitor. For clinical glaucoma management, fundus photographs are primarily used to image the $\mathrm{ONH}$. This allows the clinician to make a better judgment of the possible structural progression of the disease. A problem that appears with photographical methods is that results strongly depend on the magnification of the image. As such, the most frequently used parameter used to describe the $\mathrm{ONH}$ is the cup/disc ratio, which compares the diameter of the "cup" of the optic disc with the total diameter of the optic disc. Given that the cup/disc ratio is a relative measure, it is independent of the magnification of the image. Other frequently used parameters are the mean cup/disc diameter ratio, the mean vertical cup/disc diameter ratio and the ratio of the horizontal-tovertical cup-to-disk diameter ratio. The last-mentioned has the advantage of being independent of the size of the $\mathrm{ONH}$ and of the magnification of the fundus camera (Samarawickrama et al. 2012). Attempts have also been made to grade the nerve fiber layer based on fundus photographs (Quigley et al. 1993). In clinical routine, however, this is often difficult, particularily if the quality of the fundus photographs is not adequate.

Confocal scanning laser ophthalmoscopy has become a standard tool in imaging the $\mathrm{ONH}$. As its main advantage, confocal scanning laser ophthalmoscopy allows threedimensional imaging of the $\mathrm{ONH}$ and the adjacent tissues. This approach was commercialized as the Heidelberg Retina Tomograph more than 20 years ago (Heidelberg Engineering, Heidelberg, Germany). The system uses a 670 -nm diode laser to scan the retina and acquires a twodimensional topographic reflectance map. The confocal principle ensures that the depth from which reflected light reaches the detector is restricted to a narrow range centered around the focal plane on the posterior eye pole. A detector measures the intensity of the reflected and back-scattered light and a three-dimensional image is computed from the sectional images. With the Heidelberg Retina Tomograph, a scan depth between 0.5 and $4.0 \mathrm{~mm}$ can be chosen thereby providing an image consisting in $384 \times 384$ pixels. The transversal resolution is approximately $10 \mu \mathrm{m}$ and is limited by the optics of the eye, whereas the theoretical axial resolution is $300 \mu \mathrm{m}$. Peak-to-peak resolution in the axial plane is, however, considerably better with values ranging from 50 to $60 \mu \mathrm{m}$. The software processes the information into a colorcoded topographic map of the optic nerve. A critical step in the procedure lies in the drawing of the contour line around the border of the optic disc. The software automatically places a reference plane $50 \mu \mathrm{m}$ below and parallel to the peripapillary retinal surface, i.e., the optic disk contour line, which is then used to calculate the thickness and crosssectional area of the retinal nerve fiber layer. The software of the Heidelberg Retina Tomograph calculates structurerelated measurements describing the cup shape, cup area, cup volume, cup-to-disk ratio, rim area and rim volume. A parameter that is widely used for detecting glaucoma progression is the so-called Moorfields Regression Analysis, which relates the rim area to the area of the excavation dependent on the position of the contour line. If the calculated values for each segment of the $\mathrm{ONH}$ are within two standard deviations of a normal data set, data are considered as normal. As a measure independently of the contour line, the so-called glaucoma probability score has been introduced. Here, the optic disc and the parapapillary retinal topography are analyzed and a three-dimensional model is calculated by using five shape-based measurements including cup size, cup depth, rim steepness and vertical and horizontal parapapillary nerve fiber layer curvatures. The glaucoma probability score is then estimated as the probability that the model shows structural differences from the normal structure of the $\mathrm{ONH}$, again compared with a normal database. Numerous studies have been performed in order to evaluate the sensitivity and specificity of this technique to detect glaucoma (Andersson et al. 2011; Jindal et al. 2010; Kilintzis et al. 2011; Strouthidis et al. 2010).

Scanning laser polarimetry measures the phase shift of polarized laser light as it passes through the retinal nerve fiber layer (Da Pozzo et al. 2009). The system was 
commercialized more than 20 years ago (GDx; Carl Zeiss Meditec, Dublin, Calif., US). The technology was the first to provide a quantitative measurement of the retinal nerve fiber layer. In the earlier version of the system, imaging artifacts attributable to corneal birefringence were a common problem but have since been overcome to a large degree by the introduction of a variable corneal polarization compensator (GDxVCC). A remaining problem is, however, that atypical retardation patterns caused by penetration of light into the sclera can be found in a subtype of glaucoma patients (Gotzinger et al. 2008).

Optical coherence tomography (OCT) is a technique that was introduced in the early 1990s and generates images by measuring the echo time delay of the light reflected and back-scattered from ocular tissues (Drexler and Fujimoto 2008). Originally, time-domain detection was used in OCT and the measurement of the time delay was achieved by moving a mirror in a Michelson interferometer. With the introduction of Fourier domain OCT, a significant improvement in sensitivity and acquisition speed was achieved, because an entire A-scan could be obtained simultaneously rather than sequentially.

This method has allowed the imaging of the $\mathrm{ONH}$ and the retinal nerve fiber layer with unprecedented resolution, reproducibility and sensitivity (Sakata et al. 2009). Recently, the possibility of extracting the thickness of the ganglion cell layer has been explored (Fig. 1). Originally, the focus was directed toward automatic measurement of the combined thickness of the retinal nerve fiber layer thickness, ganglion cell layer thickness and the inner plexiform layer thickness (Kim et al. 2010). The summed thickness of these three layers is usually termed the ganglion cell complex. More recently, the combined measurement of the thickness of the ganglion cell layer and the inner plexiform layer has been evaluated and proven to be useful in discriminating between healthy and glaucomatous eyes (Mwanza et al. 2012; Takayama et al. 2012).

Interestingly, OCT can be combined with other principles to allow for the extraction not only of structural but also of functional data. Many different approaches for functional OCT have been successfully used (Drexler and Fujimoto 2008). In the context of this review, polarization-sensitive OCT is of major interest, because it allows the measurement of the birefringence of the retinal nerve fiber layer (Pircher et al. 2011). Indeed, polarization-sensitive OCT maps might be an attractive approach for early glaucoma detection, based on their ability to quantify the density of ganglion cell axons and their microtubules (Gotzinger et al. 2008). Another interesting approach might be to quantify retinal blood flow, which supplies RGCs with oxygen and nutrients. Recently, significant advances have been made in measuring retinal blood flow based on Doppler OCT (Baumann et al. 2011; Werkmeister et al. 2008, 2012a, 2012b). Other extensions of OCT techniques such as adaptive optics OCT will be discussed later in this review.

The importance of imaging in glaucoma might even increase with an enhanced understanding of the structurefunction relationship. One of the key problems is that clinical measurements of both structure and function show a wide variability, making judgments on the degree of glaucomatous damage difficult. The combination of structural and functional data is therefore an attractive approach in order to improve decision making. Although glaucoma is agreed to be associated with both progressive loss of visual field and proceeding morphological changes, these changes are not necessarily detected simultaneously in an individual patient. When comparing structural and functional parameters, one has to consider that visual field sensitivity is usually reported in a logarithmic scale making direct comparison with structural data difficult (Malik et al. 2012). When perimetric sensitivity is expressed in linear units, a linear relationship is seen between RGC density and perimetric sensitivity (Schlottmann et al. 2004). When small areas of the retina are stimulated, as occurs in perimetry, the area of retina stimulated and the visual sensitivity are linearly related, a principle that is usually referred to as Ricco's law. Clinical studies have provided evidence that the structural damage in glaucoma precedes the functional change, a condition that has been termed pre-perimetric glaucoma. The idea of this concept is that the eye has a functional reserve whereby early structural damage does not directly lead to functional damage. This hypothesis is mainly based on the observation that, in early stages of the disease, the structural damage predominates, whereas in the later stages, functional damage predominates. This, however, only holds true if visual field sensitivity is measured on a logarithmic
Fig. 1 Optical coherence tomography (OCT) image of a human retina as obtained with a standard OCT system. Note the clear delineation of the major retinal layers including the RGC layer complex. Image acquired and processed with Spectralis (Heidelberg Engineering, Heidelberg, Germany)

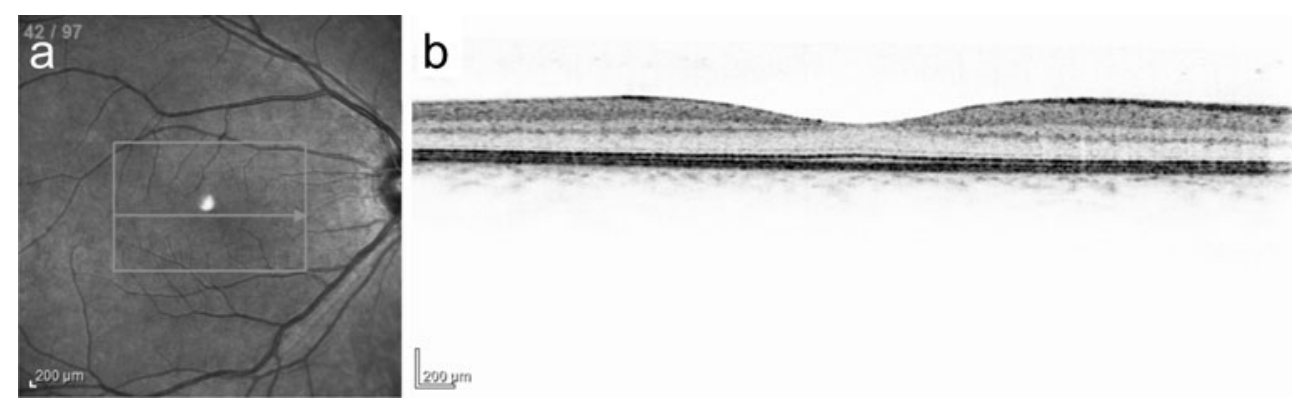


scale. When both visual fields and structural data are reported in a linear scale, it becomes evident that both structure and function are lost in parallel in glaucoma (Garway-Heath et al. 2000, 2002). In clinical pratice, however, either functional or structural damage can be detected earlier depending on the reproducibility and sensitivity of data for a given individual. When interpreting data from current techniques in studies of retinal nerve fiber layers, one needs to consider that such data also include non-neuronal elements such as glial tissues and blood vessels. This means that, even if the visual field is completely lost, retinal nerve fiber layer thickness will not decline to zero. Therefore, in the next few years, combined structural and functional data will probably become available for monitoring glaucoma in clinical practice (Bizios et al. 2011). A recent study has indicated that the relationship between structure as assessed by a scanning laser ophthalmoscope and function as assessed by flicker-defined form perimetry and frequency-doubling technology perimetry is even stronger than with standard automated perimetry (Lamparter et al. 2012).

\section{The retinal ganglion cell}

The RGCs are a heterogeneous population of postmitotic neurons. In the mouse retina, they comprise approximately $1 \%$ of all cells (Young 1985). The RGCs receive an input signal from bipolar and amacrine cells. Various subtypes of RGCs exist in the mammalian retina but the number of functional types remains unknown (Masland 2012). For imaging purposes, we need to differentiate between midget and parasol RGCs, which anatomically can easily be differentiated. The ON and OFF types of these cells can be classified, because they are located in different layers of the retina. RGCs are evenly spaced with respect to other cells of the same type, but not to other retinal cell types, even if they receive input from these cells.

The axons of the RGCs have an average length of approximately $50 \mathrm{~mm}$ with axonal bundles being separated by glial cells. The RGC axons become myelinated with oligodendrocytes behind the lamina cribrosa and form synapses with cells mostly in the lateral geniculate nucleus but also in the dienecephalic centers and the superior culliculus. RGCs show a high metabolic turnover associated with dendritic summation and action potential generation, partially explaining their vulnerability and dependence on adequate mitochondrial function.

RGCs respond to illumination based on the so-called receptive field, which usually measures approximately $1 \mathrm{~mm}$ in diameter (Mariani 1989). Hence, a single RGC receives input from many photoreceptors and from many inner nuclear layer neurons. Adjacent RGCs have overlapping receptive fields and obtain input from slightly different parts of the visual field. Whereas some sub-types of RGCs receive their input primarily from bipolar cells, others receive input primarily from amacrine cells.

In glaucoma, RGCs might die not only because of axonal degradation but also because of the activation of glial cells and the oxidative stress of immunological processes (Munemasa and Kitaoka 2012). The relative importance of these mechanisms is unknown. A large body of experimental evidence has shown that, in glaucoma, RGCs die by apoptosis. Interestingly, in animal models, experimental IOP elevation has been observed to activate both pro- and anti-apoptotic pathways. Before RGCs become apoptotic, their dendrites undergo significant morphological alterations (Liu et al. 2011). Several primate studies have shown that changes in the dendritic field, such as thinning, reduction of dendritic process diameter at branching points and alterations on the dendritic tree, also precede the loss of neurons in the lateral geniculate nucleus (Gupta et al. 2007; Weber et al. 1998). The mechanisms underlying dendritic degeneration prior to cell death are unclear but might be related to reduced axoplasmic transport (Agudo-Barriuso et al. 2013). This is compatible with the idea that increased IOP affects the retrograde transport of metabolic products and organelles because of axonal damage at the level of the lamina cribrosa (Quigley et al. 2000; Salinas-Navarro et al. 2010).

\section{Approaches to imaging RGCs}

The quality of in vivo images that can be achieved by various imaging devices is limited by the optical aberrations of the eye, which occur mainly at the level of the cornea and the lens. Using adaptive optics, one aims to correct these aberrations in real time to obtain a resolution that is almost diffractionlimited. To do so, the aberrations of the eye need to be measured by using a wavefront sensor and subsequently compensated by using a wavefront corrector. Usually, a ShackHartmann wavefront sensor is used in conjunction with a deformable mirror employed as a wavefront corrector. The transverse resolution of current adaptive optics systems is approximately $2 \mu \mathrm{m}$ (Rossi et al. 2011). The retinal cells that are most easily accessible are cones, because they function as waveguides thereby collecting light. Imaging the inner retina is more challenging, because of the transparent nature of these layers. Nerve fiber bundles, however, can be relatively easy imaged, because they are highly reflective.

Reflectance imaging with adaptive optics also allows for the imaging of other cell types, such as astrocytes or pericytes. Imaging of RGCs remains extremely difficult, most importantly because they are almost transparent and therefore invisible in optical systems. In animal models, contrast agents can be used to improve the visualization of RGCs as described in the next paragraph but these techniques are not feasible in humans. In the outer retina, light has been recognized as toxic 
Fig. 2 In vivo fluorescence images of a ganglion cell expressing fluorescence protein obtained by using an adaptive optics confocal laser scanning instrument. a-c Images obtained from three focal planes. d Maximum intensity projection image generated from five separate focal planes. Bar $20 \mu \mathrm{m}$. Adapted with permission from Biomed Opt Express (Geng et al. 2012)
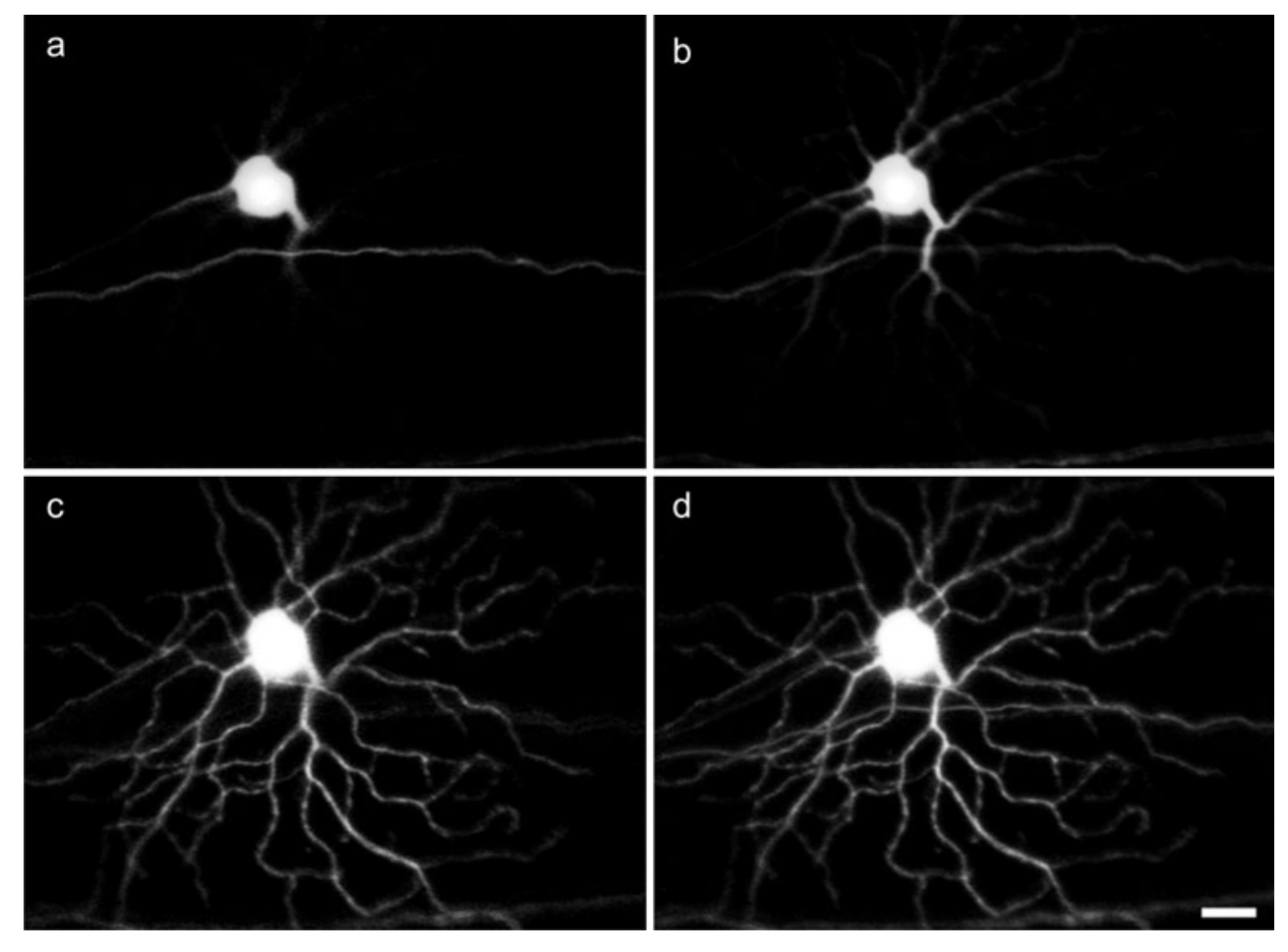

Fig. 3 Adaptive optics-optical coherence tomography $(A O-O C T)$ image of a human retina in vivo acquired over a $1^{\circ}$ retinal region. The images right are en face views of the particular retinal layers. Retinal layers from top to bottom are: nerve fiber layer $(N F L)$, ganglion cell layer $(G C L)$, outer plexiform layer $(O P L)$ and outer segment layer of photoreceptors $(O S)$. Reprinted with permission from Macmillan (copyright; Miller et al. 2011)

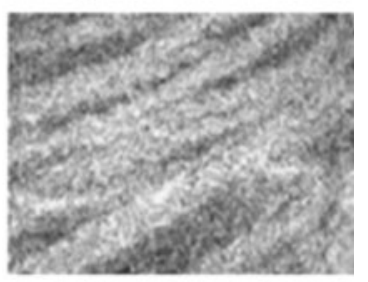

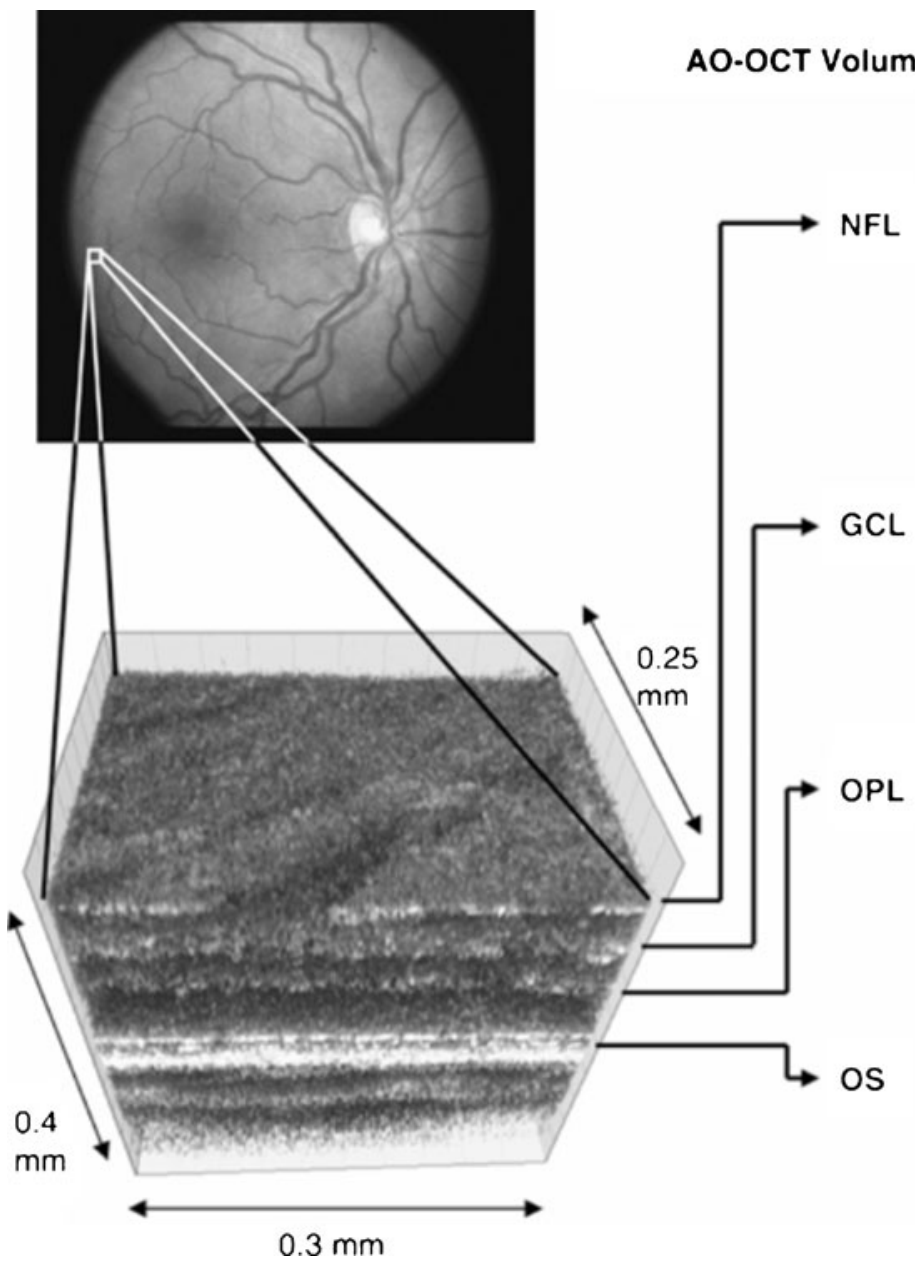

$\mathrm{GCL}$
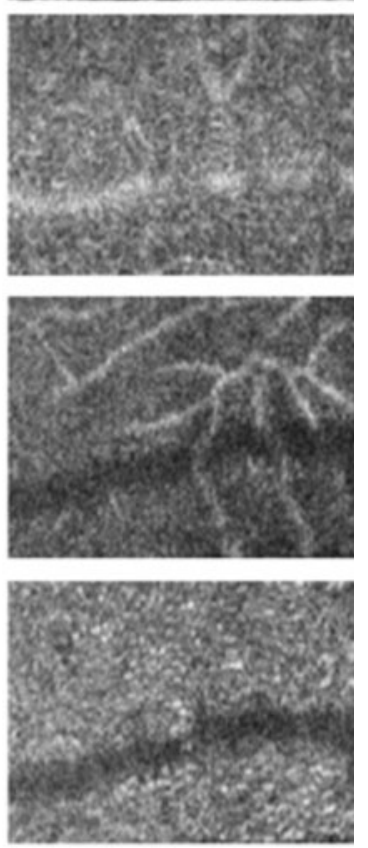
and is absorbed by photosensitizers and chromophores. In the inner retina, much less light is absorbed. In the RGCs, several components might however absorb light, particularly in the mitochondria, including complex IV or cytochrome c oxidase, cyto-chrome $\mathrm{P} 450$ and flavin proteins that include complex I, complex II and apoptosis-inducing factors (del Olmo-Aguado et al. 2012). Nevertheless, the direct imaging of RGCs in humans in vivo has not yet been achieved by using adaptive optics.

In the mouse eye, higher resolution has indeed been achieved by using adaptive optics. This has been realized with a confocal scanning adaptive optics instrument employing a wavefront sensor operating on back-scattered light (Geng et al. 2012). In these experiments, RGCs were fluorescently labeled with yellow fluorescence protein either in a transgenic mouse line that expresses yellow fluorescence protein in a small subset of RGCs or in adult C57BL/6 J mice via transduction from a retrograde viral vector (Geng et al. 2012). Figure 2 shows a ganglion cell imaged at three different focuses with three focus steps as presented by Geng et al. 2012. The three focal planes have a distance of $11.6 \mu \mathrm{m}$ each. At the innermost focus shown in Fig. 2a, two axons are in sharp focus together with the cell body. At the intermediate focus (Fig. 2b), the proximal dendrites of the cell start to come into focus. At the outermost focus, the dendritic field is sharply in focus and clearly visible (Fig. 2c). Figure 2d finally shows a maximum intensity projection image generated from several focus images.

A problem in conventional OCT is that the lateral resolution is worse than the axial resolution, because it is limited by the optical system of the eye. Recently, a combination of OCT with the principles of adaptive optics has improved the resolution to levels of $3 \times 3 \times 3 \mu \mathrm{m}^{3}$ (Miller et al. 2011). The implementation of adaptive optics into an OCT system has several advantages including increased lateral resolution, reduced speckle size and increased sensitivity to weakly scattering structures. The major drawback lies in the increased system complexity and the higher costs of such systems. Adaptive optics OCT systems have been used to study various structures at the posterior pole of the eye. This includes the imaging of the retinal microvasculature including the capillaries adjacent to the foveal avascular zone, microstructures within Henle's fiber layer, the three-dimensional photoreceptor mosaic and the retinal pigment epithelium.

For glaucoma, adaptive optics OCT might offer several interesting tools including high resolution imaging of the lamina cribrosa and microstructures within the ganglion cell layer. Figure 3 shows an example of a retinal image that can be achieved by using adaptive optics OCT within a given volume of retinal tissue (Miller et al. 2011). For acquiring the images, the focus is systematically shifted through different depths. Extracted en face slices (from top to bottom) of individual retinal nerve fiver bundles, microstructures in the ganglion cell layer, retinal capillaries and outer segments of cone photoreceptors are shown. Figure 3 makes it clear that combining adaptive optics with OCT might also be a promising approach for studying the cross-sectional profile of individual nerve fiber bundles. Interestingly, by using this technique, individual nerve fiber bundles can be identified in such images (Kocaoglu et al. 2011), even in repeated sessions, making this approach attractive for studying glaucoma progression. Further improvements in image quality might be possible by using high-speed cameras.

Another promising approach lies in the detection of apoptosing retinal cells (DARC; Cordeiro et al. 2011). Fluorescently labeled annexin $\mathrm{V}$ is used in combination with conventional ophthalmoscopy to visualize the apoptosis of RGCs. DARC enables the longitudinal observation of glaucomatous RGC death in animal models of glaucoma. Currently, however, this imaging approach is restricted to experimental animals. The use of this technology in humans includes several challenges including safety, invasiveness, sensitivity and specificity (Cordeiro et al. 2011). In addition, the number of RGCs that are undergoing apoptosis at a certain period of time in the healthy versus the glaucomatous eye is unknown, which makes the interpretation of the results difficult. Nevertheless, the method has significant potential in monitoring the disease process in glaucoma.

\section{Conclusions and future directions}

Imaging has tremendously improved in ophthalmology over the last few years. In clinical routine, OCT has started its triumphant advance in the management of glaucoma, as it has in many other eye diseases. Several promising approaches have recently been introduced including functional OCT, adaptive optics and its combination with OCT and DARC. With these techniques, we are coming closer to the aim of visualizing RGCs, their function, their metabolism and potentially their death in vivo. This is associated with the hope of improved glaucoma care and tools for evaluating neuroprotective strategies in glaucoma.

Open Access This article is distributed under the terms of the Creative Commons Attribution License, which permits any use, distribution and reproduction in any medium, provided the original author(s) and the source are credited.

\section{References}

Agudo-Barriuso M, Villegas-Perez M, Imperial JM de, Vidal-Sanz M (2013) Anatomical and functional damage in experimental glaucoma. Curr Opin Pharmacol 13:5-11

Andersson S, Heijl A, Bengtsson B (2011) Optic disc classification by the Heidelberg Retina Tomograph and by physicians with varying experience of glaucoma. Eye (Lond) 25:1401-1407 
Baumann B, Potsaid B, Kraus MF, Liu JJ, Huang D, Hornegger J, Cable AE, Duker JS, Fujimoto JG (2011) Total retinal blood flow measurement with ultrahigh speed swept source/Fourier domain OCT. Biomed Opt Express 2:1539-1552

Bizios D, Heijl A, Bengtsson B (2011) Integration and fusion of standard automated perimetry and optical coherence tomography data for improved automated glaucoma diagnostics. BMC Ophthalmol 11:20

Burgoyne CF (2011) A biomechanical paradigm for axonal insult within the optic nerve head in aging and glaucoma. Exp Eye Res 93:120-132

Cherecheanu AP, Garhofer G, Schmidl D, Werkmeister R, Schmetterer L (2013) Ocular perfusion pressure and ocular blood flow in glaucoma. Curr Opin Pharmacol 13:36-42

Cordeiro MF, Migdal C, Bloom P, Fitzke FW, Moss SE (2011) Imaging apoptosis in the eye. Eye (Lond) 25:545-553

Da Pozzo S, Marchesan R, Ravalico G (2009) Scanning laser polarimetry-a review. Clin Exp Ophthalmol 37:68-80

del Olmo-Aguado S, Manso AG, Osborne NN (2012) Light might directly affect retinal ganglion cell mitochondria to potentially influence function. Photochem Photobiol 88:1346-1355

Drexler W, Fujimoto JG (2008) State-of-the-art retinal optical coherence tomography. Prog Retin Eye Res 27:45-88

Engelhorn T, Michelson G, Waerntges S, Otto M, El-Rafei A, Struffert T, Doerfler A (2012) Changes of radial diffusivity and fractional anisotropy in the optic nerve and optic radiation of glaucoma patients. ScientificWorldJournal 2012:849632

Garway-Heath DF, Caprioli J, Fitzke FW, Hitchings RA (2000) Scaling the hill of vision: the physiological relationship between light sensitivity and ganglion cell numbers. Invest Ophthalmol Vis Sci 41:1774-1782

Garway-Heath DF, Holder GE, Fitzke FW, Hitchings RA (2002) Relationship between electrophysiological, psychophysical, and anatomical measurements in glaucoma. Invest Ophthalmol Vis Sci 43:2213-2220

Geng Y, Dubra A, Yin L, Merigan WH, Sharma R, Libby RT, Williams DR (2012) Adaptive optics retinal imaging in the living mouse eye. Biomed Opt Express 3:715-734

Gotzinger E, Pircher M, Baumann B, Hirn C, Vass C, Hitzenberger CK (2008) Analysis of the origin of atypical scanning laser polarimetry patterns by polarization-sensitive optical coherence tomography. Invest Ophthalmol Vis Sci 49:5366-5372

Gramlich OW, Bell K, Thun und Hohenstein-Blaul N von, Wilding C, Beck S, Pfeiffer N, Grus FH (2013) Autoimmune biomarkers in glaucoma patients. Curr Opin Pharmacol 13:90-97

Gupta N, Ly T, Zhang Q, Kaufman PL, Weinreb RN, Yucel YH (2007) Chronic ocular hypertension induces dendrite pathology in the lateral geniculate nucleus of the brain. Exp Eye Res 84:176-184

Jindal S, Dada T, Sreenivas V, Gupta V, Sihota R, Panda A (2010) Comparison of the diagnostic ability of Moorfield's regression analysis and glaucoma probability score using Heidelberg retinal tomograph III in eyes with primary open angle glaucoma. Indian J Ophthalmol 58:487-492

Kilintzis V, Pappas T, Chouvarda I, Salonikiou A, Maglaveras N, Dimitrakos S, Topouzis F (2011) Novel Heidelberg retina tomograph-based morphological parameters derived from optic disc cupping surface processing. Invest Ophthalmol Vis Sci 52:947-951

Kim NR, Lee ES, Seong GJ, Kim JH, An HG, Kim CY (2010) Structure-function relationship and diagnostic value of macular ganglion cell complex measurement using Fourier-domain OCT in glaucoma. Invest Ophthalmol Vis Sci 51:4646-4651

Kocaoglu OP, Cense B, Jonnal RS, Wang Q, Lee S, Gao W, Miller DT (2011) Imaging retinal nerve fiber bundles using optical coherence tomography with adaptive optics. Vis Res 51:1835-1844

Lamparter J, Russell RA, Schulze A, Schuff AC, Pfeiffer N, Hoffmann EM (2012) Structure-function relationship between FDF, FDT,
SAP, and scanning laser ophthalmoscopy in glaucoma patients. Invest Ophthalmol Vis Sci 53:7553-7559

Liu M, Duggan J, Salt TE, Cordeiro MF (2011) Dendritic changes in visual pathways in glaucoma and other neurodegenerative conditions. Exp Eye Res 92:244-250

Malik R, Swanson WH, Garway-Heath DF (2012) "Structure-function relationship" in glaucoma: past thinking and current concepts. Clin Exp Ophthalmol 40:369-380

Mariani AP (1989) Synaptic organization of classical neurotransmitter phenotypes in the primate retina. Neurosci Res Suppl 10:S101-S116

Masland RH (2012) The neuronal organization of the retina. Neuron 76:266-280

Medeiros FA, Lisboa R, Weinreb RN, Girkin CA, Liebmann JM, Zangwill LM (2012) A combined index of structure and function for staging glaucomatous damage. Arch Ophthalmol 130:1107-1116

Miller DT, Kocaoglu OP, Wang Q, Lee S (2011) Adaptive optics and the eye (super resolution OCT). Eye (Lond) 25:321-330

Mozaffarieh M, Flammer J (2013) New insights in the pathogenesis and treatment of normal tension glaucoma. Curr Opin Pharmacol 13:43-49

Munemasa Y, Kitaoka Y (2012) Molecular mechanisms of retinal ganglion cell degeneration in glaucoma and future prospects for cell body and axonal protection. Front Cell Neurosci 6:60

Mwanza JC, Durbin MK, Budenz DL, Sayyad FE, Chang RT, Neelakantan A, Godfrey DG, Carter R, Crandall AS (2012) Glaucoma diagnostic accuracy of ganglion cell-inner plexiform layer thickness: comparison with nerve fiber layer and optic nerve head. Ophthalmology 119:1151-1158

Nucci C, Martucci A, Cesareo M, Mancino R, Russo R, Bagetta G, Cerulli L, Garaci FG (2013) Brain involvement in glaucoma: advanced neuroimaging for understanding and monitoring a new target for therapy. Curr Opin Pharmacol 13:128-133

Osborne NN (2010) Mitochondria: their role in ganglion cell death and survival in primary open angle glaucoma. Exp Eye Res 90:750-757

Pircher M, Hitzenberger CK, Schmidt-Erfurth U (2011) Polarization sensitive optical coherence tomography in the human eye. Prog Retin Eye Res 30:431-451

Quigley HA (2011) Glaucoma. Lancet 377:1367-1377

Quigley HA, Reacher M, Katz J, Strahlman E, Gilbert D, Scott R (1993) Quantitative grading of nerve fiber layer photographs. Ophthalmology 100:1800-1807

Quigley HA, McKinnon SJ, Zack DJ, Pease ME, Kerrigan-Baumrind LA, Kerrigan DF, Mitchell RS (2000) Retrograde axonal transport of BDNF in retinal ganglion cells is blocked by acute IOP elevation in rats. Invest Ophthalmol Vis Sci 41:3460-3466

Resch H, Garhofer G, Fuchsjager-Mayrl G, Hommer A, Schmetterer L (2009) Endothelial dysfunction in glaucoma. Acta Ophthalmol $87: 4-12$

Rossi EA, Chung M, Dubra A, Hunter JJ, Merigan WH, Williams DR (2011) Imaging retinal mosaics in the living eye. Eye (Lond) 25:301-308

Sakata LM, Deleon-Ortega J, Sakata V, Girkin CA (2009) Optical coherence tomography of the retina and optic nerve - a review. Clin Exp Ophthalmol 37:90-99

Salinas-Navarro M, Alarcon-Martinez L, Valiente-Soriano FJ, Jimenez-Lopez M, Mayor-Torroglosa S, Aviles-Trigueros M, Villegas-Perez MP, Vidal-Sanz M (2010) Ocular hypertension impairs optic nerve axonal transport leading to progressive retinal ganglion cell degeneration. Exp Eye Res 90:168-183

Samarawickrama C, Hong T, Jonas JB, Mitchell P (2012) Measurement of normal optic nerve head parameters. Surv Ophthalmol 57:317-336

Schlottmann PG, De Cilla S, Greenfield DS, Caprioli J, Garway-Heath DF (2004) Relationship between visual field sensitivity and retinal nerve fiber layer thickness as measured by scanning laser polarimetry. Invest Ophthalmol Vis Sci 45:1823-1829 
Schmidl D, Garhofer G, Schmetterer L (2011) The complex interaction between ocular perfusion pressure and ocular blood flow-relevance for glaucoma. Exp Eye Res 93:141-155

Strouthidis NG, Girard MJ (2013) Altering the way the optic nerve head responds to intraocular pressure - a potential approach to glaucoma therapy. Curr Opin Pharmacol 13:83-89

Strouthidis NG, Demirel S, Asaoka R, Cossio-Zuniga C, GarwayHeath DF (2010) The Heidelberg retina tomograph glaucoma probability score: reproducibility and measurement of progression. Ophthalmology 117:724-729

Takayama K, Hangai M, Durbin M, Nakano N, Morooka S, Akagi T, Ikeda HO, Yoshimura N (2012) A novel method to detect local ganglion cell loss in early glaucoma using spectral-domain optical coherence tomography. Invest Ophthalmol Vis Sci 53:6904-6913

Tezel G (2013) Immune regulation toward immunomodulation for neuroprotection in glaucoma. Curr Opin Pharmacol 13:23-31

Weber AJ, Kaufman PL, Hubbard WC (1998) Morphology of single ganglion cells in the glaucomatous primate retina. Invest Ophthalmol Vis Sci 39:2304-2320
Werkmeister RM, Dragostinoff N, Pircher M, Gotzinger E, Hitzenberger CK, Leitgeb RA, Schmetterer L (2008) Bidirectional Doppler Fourier-domain optical coherence tomography for measurement of absolute flow velocities in human retinal vessels. Opt Lett 33:2967-2969

Werkmeister RM, Dragostinoff N, Palkovits S, Told R, Boltz A, Leitgeb RA, Gröschl M, Garhöfer G, Schmetterer L (2012a) Measurement of absolute blood flow velocity and blood flow in the human retina by dual-beam bidirectional Doppler Fourier-domain optical coherence tomography. Invest Ophthalmol Vis Sci 53:6062-6071

Werkmeister RM, Palkovits S, Told R, Groschl M, Leitgeb RA, Garhofer G, Schmetterer L (2012b) Response of retinal blood flow to systemic hyperoxia as measured with dual-beam bidirectional Doppler Fourier-domain optical coherence tomography. PLoS One 7:e45876

Young RW (1985) Cell differentiation in the retina of the mouse. Anat Rec 212:199-205

Yucel YH, Gupta N (2008) Paying attention to the cerebrovascular system in glaucoma. Can J Ophthalmol 43:342-346 